\title{
Music and misogyny: a content analysis of misogynistic, antifeminist forums
}

\author{
SAM DE BOISE
}

School of Music, Theatre and Art, Örebro University, Sweden

E-mail: Sam.deBoise@oru.se

\begin{abstract}
Research exploring the relationship between misogyny and music has been divided between those who argue that certain music causes, confirms or is a manifestation of misogyny. Yet this often takes for granted the link between certain genres (predominantly hip hop, rap and metal) and misogynistic 'messages'. Instead of asking what types of music might be misogynistic, this article instead asks how music is discussed amongst those who actively espouse misogynistic views. Through content analysis of 1173 posts, from 6 'misogynistic antifeminist movement' (MAM) forums, it shows that whilst hip hop, rap and metal genres and artists are the most commonly mentioned, there is significant variation in terms of musical preferences and justifications. Whilst masculinist lyrics were the main reasons for music preferences, this study shows how MAM communities' musical judgments are a confluence of sonic and extra-musical discourses which are shaped and amplified within these online communities.
\end{abstract}

\section{Introduction}

Music has been linked to misogyny in different ways. While some argue that exposure to certain genres leads to the development of negative attitudes towards women (Kistler and Lee 2009; Lawrence and Joyner 1991; Wester et al. 1997; Aubrey et al. 2011; Fischer and Greitemeyer 2006), others suggest that these genres attract those who already display more aggressive, violent or 'maladaptive' tendencies (Garrido and Schubert 2013; Lozon and Bensimon 2014). Much of this research has tended to focus predominantly on rap, hip hop and metal, relating attitudes to misogynistic lyrics or 'aggressive' sonic characteristics. However, musicological research has suggested that cultural expressions of misogyny are also observable in non-lyrical and Western classical music (see, for instance, McClary 1991; Cook and Tsou 1994; Citron 1993).

Music is implicated in shaping gendered attitudes and expectations and should be understood as an expression of cultural gender norms more broadly (Moisala and Diamond 2000). Yet studies on music and misogyny often start by predefining specific genres or pieces and then 'working backwards' to reveal or test misogynistic content. As such they begin with the presumption that certain aesthetics cause, 
attract or are a manifestation of misogyny. This leads to confirmation bias in that researchers, rather than listeners, choose the genres/music, and establish tentative causal links between music and attitudes. Most commonly, song lyrics have been coupled with predetermined survey responses or artificial, experimental scenarios which fail to explore how other factors influence listeners' interpretations. Critical musicology, in contrast, is adept at identifying gendered narratives in musical form and structure but places more analytical emphasis on the researcher's interpretation than how other people justify their listening patterns.

Rather than asking what misogynistic musics are, this article instead asks: what musics are listened to or disliked by a group who already openly express misogynistic attitudes? To answer this, the article focuses on those with links to misogynistic antifeminist movements (MAMs). These are groups which have been defined largely through their embrace of a masculinist politics which posits that men are inherently biologically different and superior to women (Mellström 2016; Blais and Dupuis-Déri 2012; Brittan 2001), as well as expressing explicitly misogynistic and antifeminist views (Gotell and Dutton 2016; Moi 2006).

Through a content analysis of a corpus of 1173 posts from six transnational MAM forums, the article poses two key questions. Firstly, which artists and kinds of music are most frequently mentioned in terms of preferences and dislikes? Secondly, how do the participants justify their judgments with respect to the lyrical, sonic and extra-musical qualities of music? By adopting this approach, this article explores the correspondence between particular music preferences and openly misogynistic views and demonstrates how forum users' motivations and evaluations rely on a range of intra- and extra-musical factors. This approach seeks to contribute to understanding the link between misogynistic and antifeminist sentiments in relation to music, as both a correspondence of aesthetics and attitudes, and a discursive amplification of particular ways of interpreting music within specific 'taste communities' (see McLeod 2001).

The article first details how music's relationship to misogyny has been studied so far. It then outlines the characteristics of contemporary MAMs in primarily Western European and US contexts. The method, procedure, dataset and ethics are subsequently explained, before indicating the key findings in terms of both music preferences and dislikes. The article then explores the relationships between evaluations, justifications and the music, highlighting that, while there are particular links between MAM group members and particular aesthetic choices, the relationship of misogyny to music is multi- rather than unidirectional. Crucially, these relationships extend beyond particular genres and lyrics, and implicate the confluence of historical discourses, intra-sonic dimensions and current geopolitics in formulating aesthetic judgments.

\section{Music and misogyny}

To date, there is no research on the links between music and MAMs. However there is a well-documented literature looking at music's potential for promoting or encouraging gendered forms of harm, particularly among groups of men (Fischer and Greitemeyer 2006; Barongan and Nagayama 1995; Aubrey et al. 2011), as well as music's role as a tool for recruitment and spreading messages among far-right organisations, which largely comprise men (Dyck 2017; Teitelbaum 2017; Shekhovtsov 2012). 
Methodologically, research on the relationship between music and misogyny is divided between those who focus on how broader gendered structures can be revealed through the study of musical texts and/or aesthetics, and those who focus on demonstrating the relationships between musics, attitudes and behaviour through taking human participants as their study objects. While the latter have focused on music's ability to unconsciously influence people's attitudes, the former have looked to explain gendered aggression and violence, particularly through an analysis of the sonic characteristics of (predominantly) popular music genres. These have largely focused on rock, rap, hip hop and heavy metal genres, noting particularly that they connect to misogyny through 'masculine' sonic features, including distorted guitars, 'sinister' chord progressions, atonality and discordance, bass-heavy production, prominent or accented backbeats, shouted, screamed or growled vocals, rapid or staccato vocal delivery and fast tempos (Walser 1993; Iwamoto 2003; Järviluoma et al. 2003; Weitzer and Kubrin 2009; McLeod 2009). This has aimed to show, particularly, how 'masculine' traits such as power, aggression, control and dominance can be heard as well as visibly performed (see, for example, Frith and McRobbie 1978).

In addition, 'artistic' and Western classical traditions have been shown to represent misogyny in various ways. This is both through use of structural dynamics and techniques and through compositional traditions constructed through appeals to gendered and racialised notions of transcendence, which simultaneously render male privilege invisible (DeNora 1997; Citron 1993). For instance, as McClary (1991, pp. 61-63) points out, not only have Western operatic conventions historically meant that women protagonists suffer brutal deaths, but this brutality is also underscored sonically through male characters' celebration of this violence. Furthermore, McClary's famous analysis of Beethoven's 9th Symphony notes how it evokes both 'desire' and 'murderous rage', symbolic of men's violence against women more generally (p. 128). ${ }^{1}$

Experimental psychological approaches have more directly focused on popular music lyrics' impact on human participants, with hip hop, rap and metal, again, regarded as the causes, par excellence, of misogynistic attitudes. For instance, a range of studies, prompted by debates around music's capacity for social harm in the 1980s and 1990s, looked to investigate the potentially damaging messages of heavy metal and hip hop through experimental designs which are taken as a proxy for 'real life' behaviours (Lawrence and Joyner 1991; Wester et al. 1997; Fischer and Greitemeyer 2006; Barongan and Nagayama 1995). ${ }^{2}$ These 'media effect' models were more common in the 1990s but have not disappeared since then (for example Kistler and Lee 2009; Aubrey et al. 2011). On the other hand, while these approaches have tended to treat music as a cause of misogynistic attitudes, more survey-based, social psychological research has instead indicated that certain personalities are drawn to violent themes in particular music genres, focusing again largely on rap, hip hop and metal (Garrido and Schubert 2013; Lozon and Bensimon 2014). This means that, even if the causes are seen to differ, there is still an assumed causal link between particular aesthetics and attitudes.

1 This was originally explained as analogous to sexual violence but later changed.

2 Promoted in part and manifest in US congress debates about sexual violence in music, brought to public attention by the Parental Music Resource Centre. 
However, it is important to be cautious of claims that music listening causes certain types of behaviour or that certain types of music are inherently violent or misogynistic. There is frequently researcher bias in the design of experimental research on music and behaviour in that the researchers specify genres or pieces in advance, do not interrogate participants' understandings of genres or pieces, and rely on artificial research designs (see de Boise 2015, pp. 124-5). A variety of different interpretations around gender and sexuality in music are possible, even among songs with heterosexist or misogynistic lyrics (Jarman-Ivens 2006), and what may be considered musically violent or aggressive for one person is not necessarily the same for another. Identity does not intrinsically determine engagement with musical aesthetics but is filtered through cultural context and personal and social histories (Volgsten 2006, pp. 74-5). Thus the meanings attributed to the same pieces may vary by social location, political attitudes and geographical context.

Furthermore, the selection of 'extreme' cases does not necessarily represent a majority of listeners' practices and may reinforce stereotypes about particular genres. Weitzer and Kubrin (2009) document that between 1992 and 2000 a survey of 400 of the best-selling 'gangsta rap' songs revealed that while $22 \%$ had misogynistic lyrical themes, $78 \%$ did not. The percentage of songs with misogynistic lyrics was still significant but much less than commonly believed. This indicates that the tendency to research rap is perhaps more due to its relationship to African-American men than the fact that the music itself is 'more' misogynistic than other forms (Fried 1996). Vitally, existing research on music and misogyny does not adequately grasp complex relationships between judgments about misogynistic lyrics, a variety of musical aesthetics and misogynistic attitudes on specific populations. Thus, experimental studies confirming certain musics' misogynistic representations, instead, may reveal more about the biases of white university students in the USA (see Henry 2008) rather than any enduring truth about misogyny in particular types of music.

\section{Misogynistic antifeminist movements}

Movements looking to mobilise men against the perceived threat of gender equality go back as far as the existence of suffrage movements (Wilson 2018, p. 432), ${ }^{3}$ but have most recently been explained as an antifeminist 'backlash' (Faludi 1992), or reaction to political gains related to women's liberation and feminist movements in the 1980s and 1990s (Moi 2006; Messner 1998). In Western Europe, the US and Australia (among others), 'men's rights' movements (MRMs), have commonly organised around custody issues (Dragiewicz 2011). However, contemporary 'men's rights' movements are fragmented and the name should, at best, be interpreted as an umbrella term covering a range of issues and interests (Gotell and Dutton 2016).

What distinguishes MRMs from more explicitly MAMs is that, while MRMs are focused on institutional change, MAMs do not advocate specifically for rights. Instead they have broadly coalesced in opposition to a perceived 'feminist cultural tyranny' (García-Favaro and Gill 2016; Moi 2006; Ging 2017), and promoted explicitly phallocentric worldviews. One example is the 'pick-up artist' community, which regards women as existing solely for men's sexual gratification (see O'Neill 2018). Strategically, MRMs and MAMs also adopt different tactics and targets. The former

3 Organisations such as The League for Men's Rights (London) and The Federation for Men's Rights (Vienna) were both founded in 1926. 
aim for legal changes to institutional reforms which were largely designed to protect women and children. The latter see themselves as waging a 'culture war' against feminism in an attempt to discursively counter what is perceived to be feminism's 'cultural hegemony' (Nagle 2017). As such, discussions about 'culture', in which music plays a significant role, feature prominently in attempts to discursively articulate antifeminist narratives.

As Blais and Dupuis- Déri (2012, p. 26) argue, despite its heterogeneity, the most recent incarnations of antifeminist counter movements can be understood as social movements inasmuch as '[activists] identify themselves first and foremost as men and it is in this capacity that they see themselves as victims of women and feminists', operating with 'the goal of affecting social relationships' (p. 28). Indeed these disparate groups share a common rhetoric around 'men as victims', the perceived political dominance of feminism's impact on 'tradition' and 'culture' (Moi 2006), and strong, publicly vocal antifeminist opinions manifest in activist strategies (Messner 1998).

As noted, MAMs are not a new phenomenon. However what distinguishes 'newer' forms from previous movements, such as the 'Mythopoetic men's movement' of the 1990s (see Kimmel 1995), is their influence on mainstream media debates and politics. This has been achieved particularly through their proliferation and amplification via the 'blogosphere' and social media (Jane 2016; Nagle 2017), what has been termed the 'Manosphere', to create specific online spaces which are so hostile to women that very few women participate in them (Gotell and Dutton 2016). This online dynamic is also what distinguishes MAMs today from groups such as the Mythopoetic men's movement which were more visibly activist and geographically localised. Nonetheless, the online violence perpetrated by these groups has implications offline, as with 'involuntarily celibate' (incel) subgroups which have been linked to a number of mass shootings and violence against women (Ging 2017).

Central to MAMs' influence is the argument that 'traditional masculinity' is being devalued or is disappearing, while asserting simultaneously that it should be reclaimed. Importantly, this politics of 'masculinism' is different from 'masculinity' in the sense that while it is generally accepted that gendered behaviour and ideas of masculinity/ies are socially constructed, masculinism places a stress on biologically deterministic arguments around the inherent 'natural' superiority of men (Brittan 2001, p. 53). In short, masculinism, rather than masculinity, regards gendered behaviours as sexually dimorphic and determined by nature, stressing that (white, cisgendered) male supremacy is both desirable and normal. This is an inherently misogynistic ideology and such appeals have been crucial to the renewed success of MAMs and MRMs as well as other far right movements more generally (Blais and Dupuis-Déri 2012; Mellström 2016).

Not all those engaged in MAMs are from the Global North (see Chowdhury 2014), nor do all identify as men (see Lynn 2014). Yet the vast majority of members of MAMs have been white men from Global Northern countries. Thus, it is also necessary to be aware that nationality and race play a role in shaping MAM manifestations and discourses. MAMs do not spring from men's decline but an affective sense that white, 'traditional masculinity' - regarded as a cornerstone of 'Western civilisation' - is in decline. The idea of 'traditional masculinity', itself, therefore functions as an ahistorical imaginary which neglects changes in the definition of both behaviour and the exclusion of certain bodies when invoking a 'masculine ideal' (Forth 2008). To this end, there is considerable overlap between 'alt-right'/white nationalist groups and the type of masculinism espoused by MAM and MRA groups (Ferber 2000). 


\section{Method}

\section{Procedure}

The study was based on a content analysis (CA) of MAM web forums. The particular advantages of this are that, because web forums are not created by researchers, discussions are more 'naturalistic' and less likely to be subject to self-censorship (see Sugiura et al. 2017, p. 193). The anonymity offered online makes it more likely that attitudes, behaviours or opinions which are more likely to be harmful to women will be disclosed, than when using offline methods (see DiNitto et al. 2008).

As Weitzer and Kubrin (2009) show, CA itself offers an important way of estimating the extent of misogyny in particular types of music as well as testing stereotypes about them. Content analysis allows researchers to systematically process large quantities of information and to demonstrate statistical relationships between various qualitative judgments and assertions (Neuendorf 2017). Here, using a CA approach meant that all musics had the possibility of being included and the relative importance and value of certain artists or genres, in relation to others, could be estimated. This allows for inductively analysing patterns in the ways in which justifications are negotiated, discussed and contested in interaction with other forum users, rather than starting with predefined artists or genre categories.

Six forums renowned for their links to MAMs were first selected. The names of these have been omitted to ensure anonymity. However these sites were chosen because they reflect a broad range and are sites where MAMs are heavily active (see Nagle 2017; Ging 2017; O'Neill 2018). In February 2018 these six forums were searched for any threads discussing music preferences specifically, or the relationship of music to behaviour or attitudes. Discussions of gender equality in relation to live music events, musical 'talent' as it related to biological differences or how to 'pick up' women at music events were thus excluded from the data.

This yielded a total of 55 threads varying between 3 and 204 posts. Posts in each thread were first assigned a unique identifier, and verbatim texts for each individual post were coded in an offline SPSS datafile along with details on: (1) site/forum; (2) post year; (3) whether a specific artist, genre or discussions around music more generally were mentioned; (4) name of piece, genre and artist; (5) negative, positive or ambivalent evaluation (see Figure 5); and (6) evaluation content. Posts often mentioned several artists or genres; however, only the first four mentions of either a genre or an artist were recorded. In cases where a post made comments about more than four artists the remaining mentions were excluded unless they expressed a contrasting opinion. In a number of threads, individuals made several posts in the same thread. So as not to skew the data towards a particular person or group of individuals, where a person using the same username made a number of posts, only the first four mentions of artists or genres made by that user in the same thread were included.

Where videos or lyrics, instead of information about artists, were posted, names of artists, musicians or bands were added manually. In a handful of cases, posters referred to covers rather than originals, although this was generally made clear. Where a specific genre or type of music was mentioned, these were recorded and assigned a numerical value from 1 to 14 (see Figure 5) with discussions of 'music generally' recorded as a 15th option within the same variable. Named artists were then assigned a genre classification based on this list. Artist classifications into a genre label were based on the presence of either the posters' own classificatory statements 


\section{Number of posts about music by year}

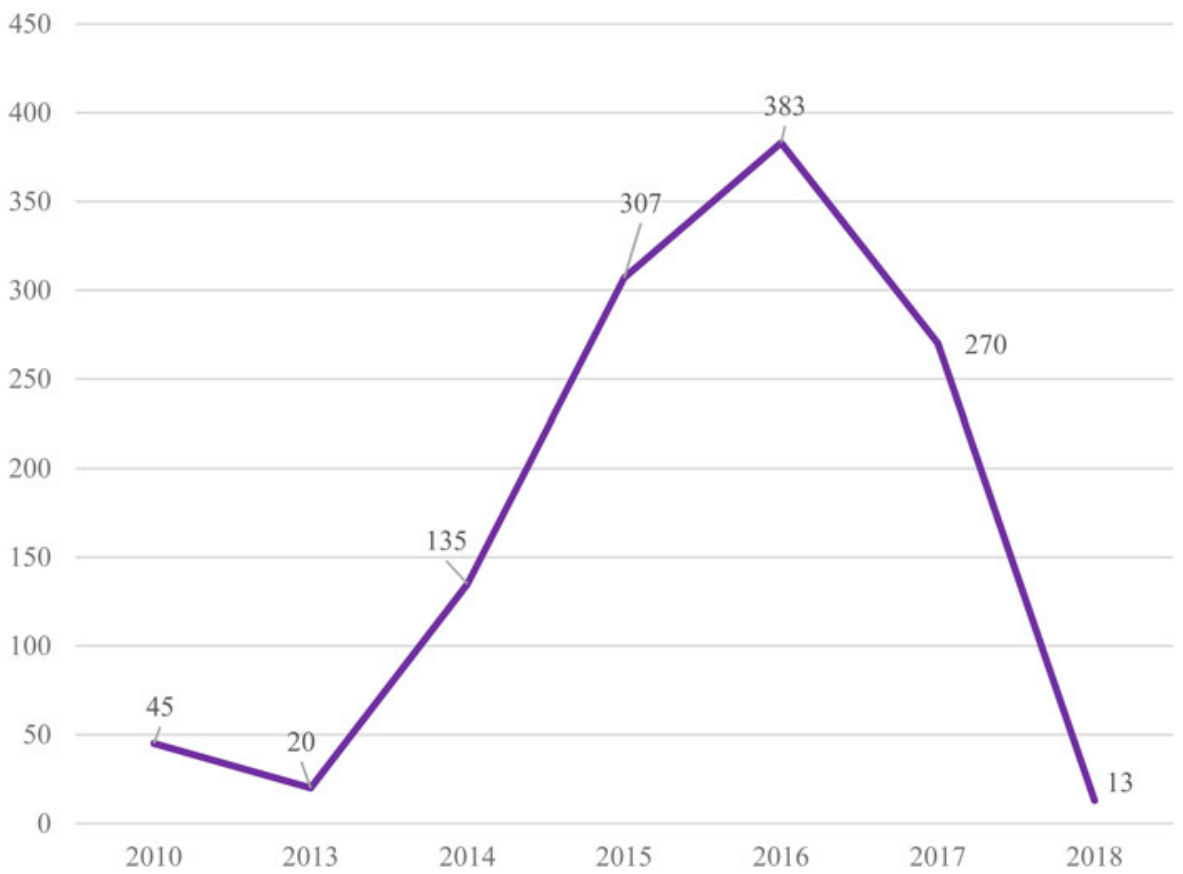

Figure 1. Number of posts about music by year.

(i.e. 'he's a rapper' or 'these guys are true country') or, in the absence of this, the artists' own genre classifications from their public websites. The genre umbrella categories had to be sufficiently broad to enable statistical comparisons and there were numerous discussions by posters around how genres should be appropriately classified.

Analysing both likes and dislikes was especially important given that patterns of social exclusion and identity formation are often expressed through the disavowal or dismissal of others' tastes (see de Boise 2015, pp. 126-34). Each evaluation was numerically coded in order to look for relationships between music preferences and motivations (see Tables 2 and 3), developing a list of the 20 most common, non-overlapping justifications for positive and negative evaluations. As with other forms of content analysis, this process is liable to interpretation coder bias (Neuendorf 2017, p. 121). To minimise this, SPSS Text-Analytics was used to identify the most common words and their relationships in order to develop preliminary thematic justification code-frames, before reiteratively coding positive and negative verbatim responses.

\section{Dataset}

In total this procedure generated 1,173 posts, ranging in date from 2010 to 2018. Most posts were made during 2014-2016 (see Figure 1) with the majority taken from Forums 1 and 2 (see Figure 2). The skew towards these sites reflects both their highprofile status among MAMs as well as their focus more generally on discussions of 


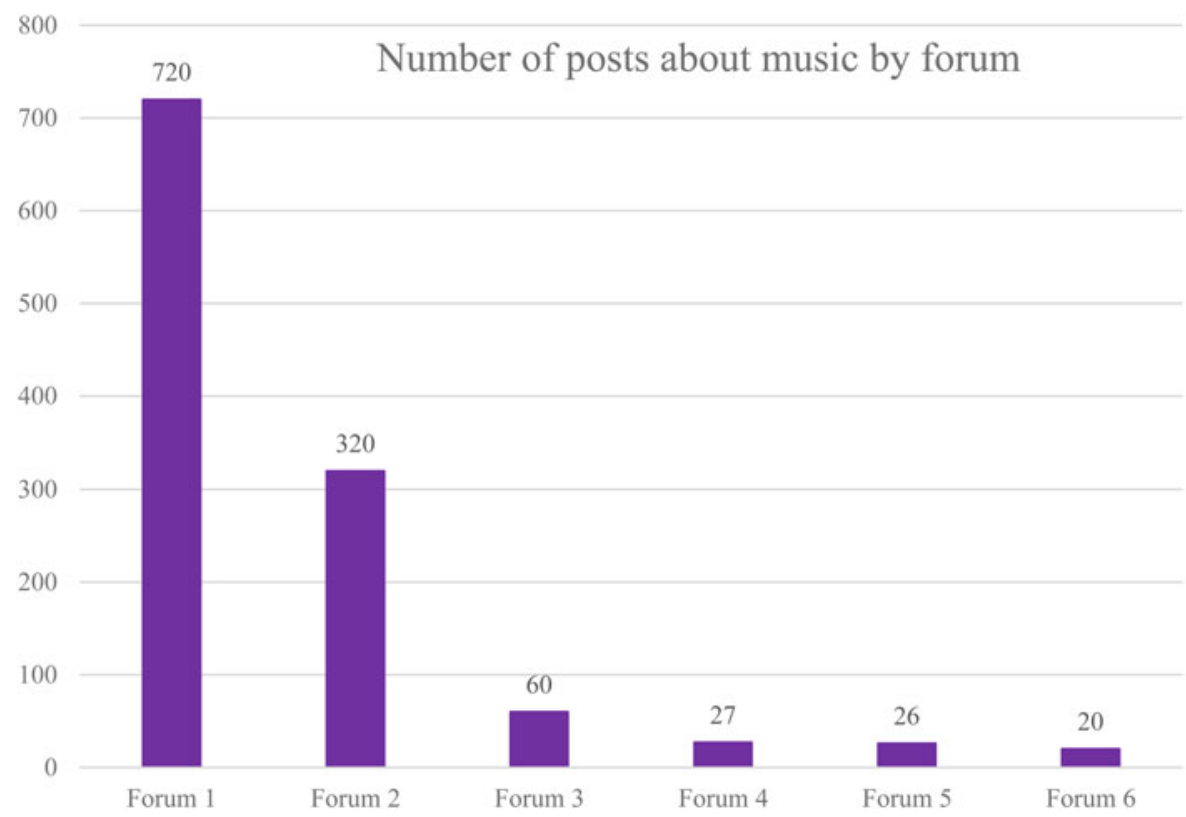

Figure 2. Number of posts about music by forum.

'cultural issues' rather than institutional reform. The peak of posts in 2016 most likely coincides with the media attention given to 'alt-right' and MRA groups, in the run-up to the 2016 US election.

These data cannot concretely identify the demographic background of posters, a limitation of the method used here. While in some cases nationality was clearly denoted - for instance with the use of US flags as avatars or nationally specific pseudonyms - there was far more discussion indicating an international audience than might be suspected on an English-language site. The lack of obvious resistance to racist messages, though, would lend support to the notion that many of the commentators were white. Numerous discussions of experiences of US and UK university life would also indicate a high representation of educated young men from Anglophone countries.

As a result of the method, it is not always possible to distinguish between where contributors are genuine in their expressions and where activists actively 'troll' MAM forum users. However, forum moderators already remove 'trolling' posts and where it was obvious, neither these nor responses to them were included in the dataset. It is also worth noting that even 'ironic' posts often do little to disrupt the sentiments of the wider communities if they are not perceived to be ironic.

\section{Analysis}

Genre, evaluation and justification variables were first re-coded in SPSS in order to estimate the overall number of mentions of specific music genres and to indicate whether positive, negative or ambiguous/ambivalent judgments were made more often in relation to specific genres or artists. Statistical significance testing was then conducted on every combination of genre, evaluation and justification variables 


\section{Type of music by no. of mentions and evaluations}

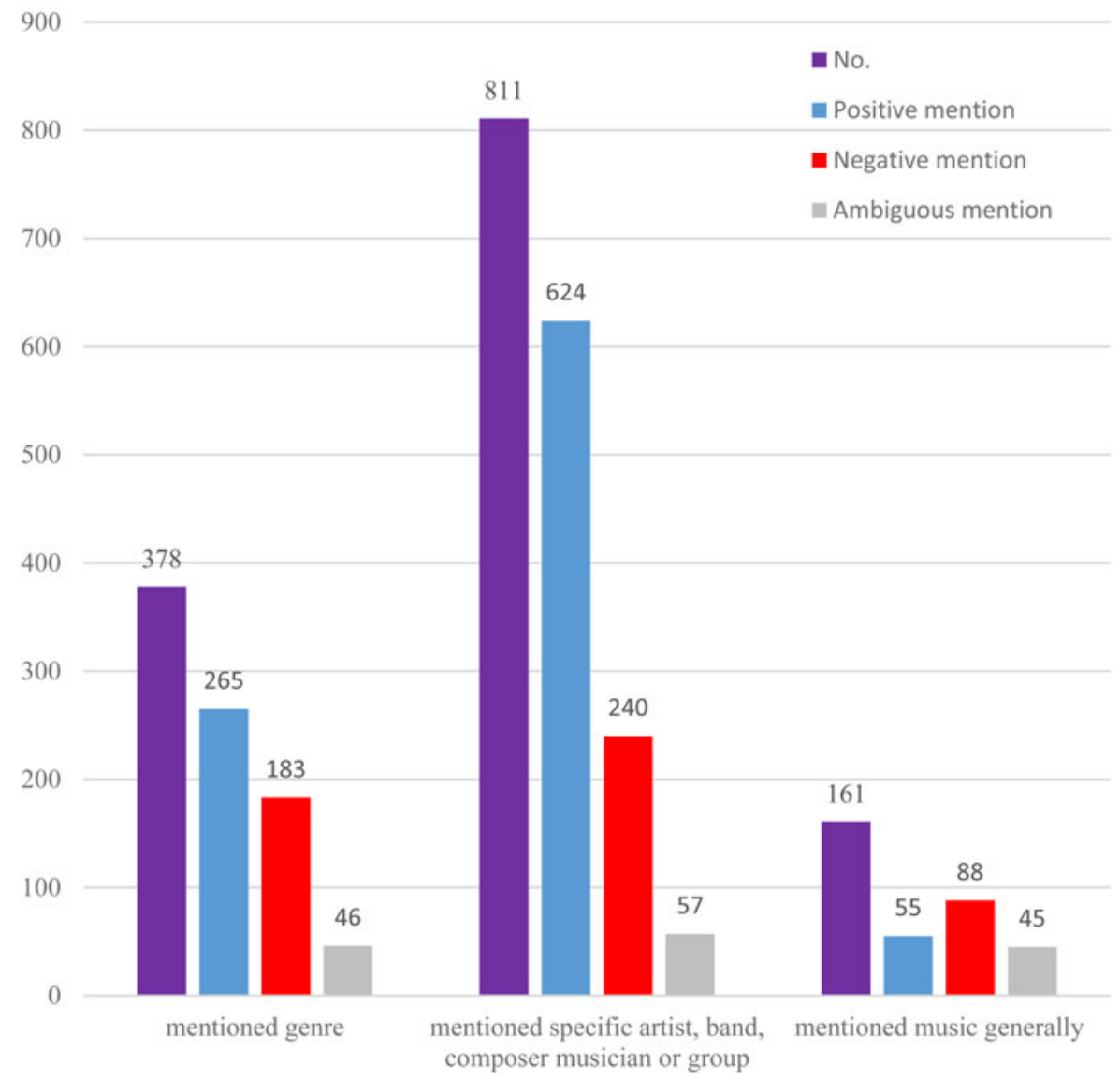

Figure 3. Type of music by number of mentions and evaluations.

using post-hoc $\chi^{2}$ tests, assuming a confidence interval of $95 \%$. The impact of forum and date on response was also controlled during analysis.

\section{Ethics}

Analysis on web forums involves a number of ethical issues. Firstly, while informed consent to use posters' comments is desirable, consent would not have been possible given that many of the posts go back several years and are posted under pseudonyms. Given the subject matter, consent would also not have been forthcoming (see discussions in Teitelbaum 2017, pp. 10-11). All posts included in the corpus were publicly visible and accessible and no deception or registration was necessary to obtain access. However every effort has been made to make sure that individuals are not identifiable from their responses, ensuring posters' right to privacy (Eynon et al. 2009, p. 188). Comments have also not been reported at an individual level and data analysis has been aggregated so as to ensure that there is 'minimal risk 


\section{Evaluations by no. of mentions}

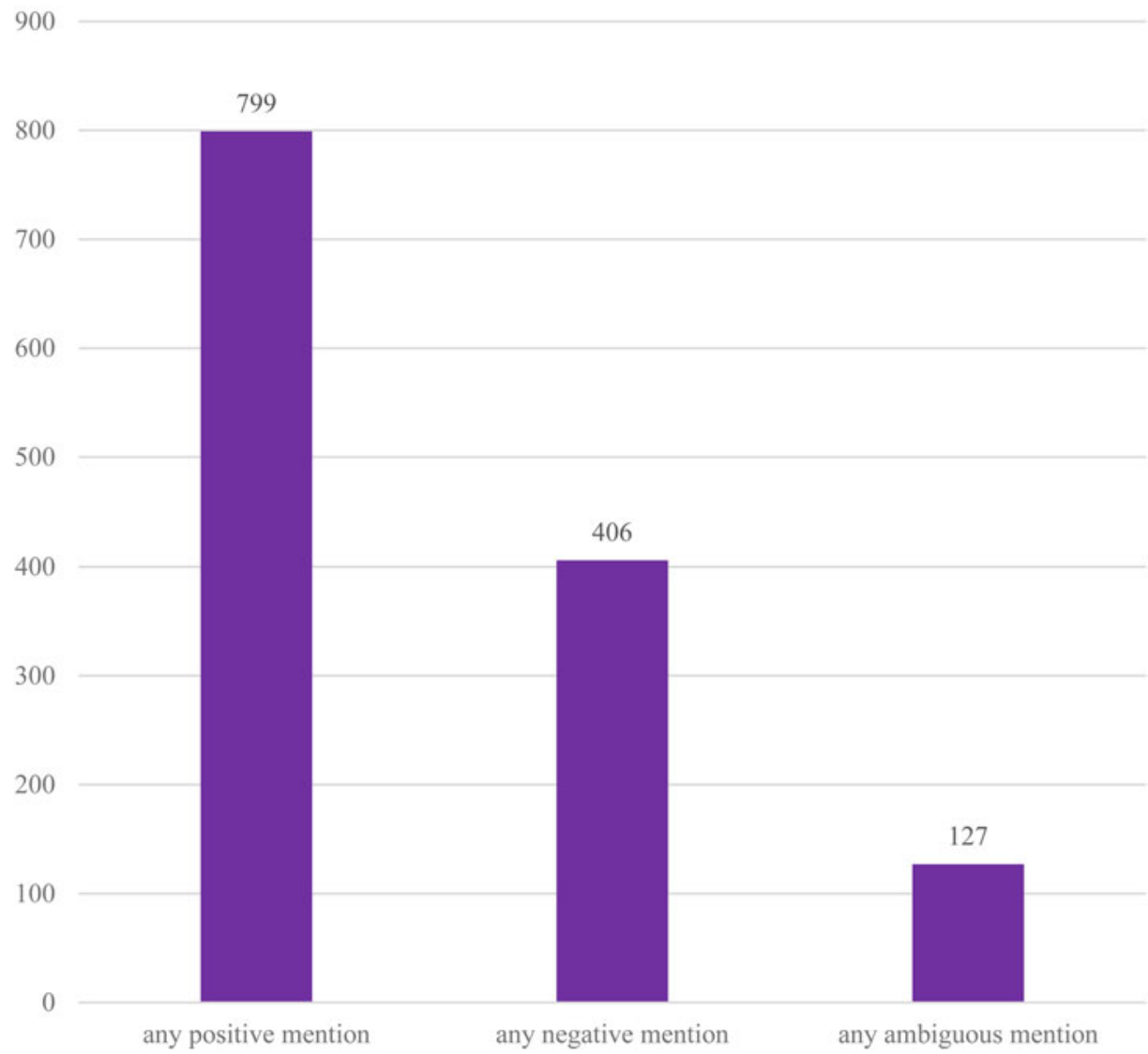

Figure 4. Evaluations by number of mentions.

[to individual forum users] and does not negatively affect the rights and well-being of subjects' (Sugiura et al. 2017, p. 191).

Furthermore, in line with the General Data Protection Regulation (GDPR), usernames/pseudonyms were not captured. Verbatim texts were coded in a second, encrypted SPSS datafile which was stored separately from the numeric data analysis file, on an offline hard drive, in a locked filing cabinet so they could not be linked to randomly generated IDs. To further avoid identification of individuals - even by their usernames - only specific artists/musicians with five mentions or more have been included in the analysis.

\section{Preferences and dislikes}

\section{Genres}

As Figure 3 indicates, in total 32\% of all posts mentioned a genre, 69\% mentioned a specific band, musician or artist and $14 \%$ focused on music generally. The genres 


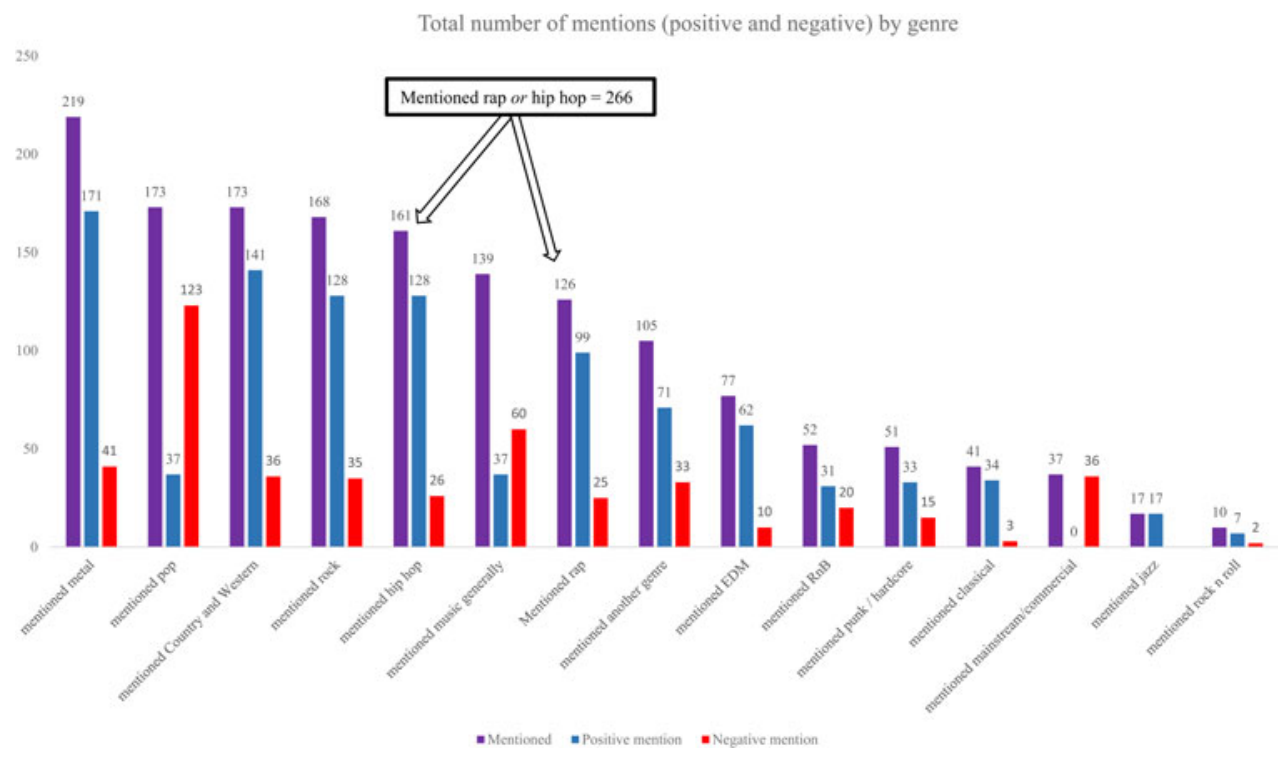

Figure 5. Total number of mentions (positive and negative) by genre.

mentioned most often were connected to metal, hip hop, pop, rock, rap and Country and Western (Figure 5), with $73 \%$ of posts making reference to at least one of these six. As Figure 5 also shows, positive evaluations were made most often about rap, hip hop, rock, country and metal, whereas ' $\mathrm{pop}^{\prime}$ and 'music generally' received mostly negative mentions $(71 \%$ among those who mentioned a pop artist or pop genre and $43 \%$ among those who mentioned music generally ${ }^{4}$ ).

Rap and hip hop artists and subgenres, when amalgamated, were mentioned in $23 \%$ of responses, with metal a close second, being discussed in $19 \%$ of posts. Country and Western artists and genres, followed closely by rock, were generally the next most frequently mentioned with both receiving overwhelmingly positive evaluations. Given the presumptive skew towards white, North American audiences on these sites, this is not surprising. However while classical and jazz artists and genres were mentioned less frequently, evaluations among these were almost unanimously positive.

There were also significant differences in the genres mentioned by forum (d.f. $=5, p=0.000$ ), although smaller sample sizes in Forums 4-6 mean that it is difficult to draw meaningful comparisons here. In addition, bands or artists associated with nu-metal or black metal sub-genre labels were most frequently denigrated within discussions on the value of metal, while distinctions around 'commercial rap' contributed most to negative responses about rap. Electronic dance music, $R$ ' $n$ ' B and punk/hardcore were mentioned far less frequently, but still accounted for a significant minority of responses.

These data indicate several things. Firstly, in line with previous research on music and misogyny, metal, rap and hip hop occupy a prominent place in the data. This suggests that, among a community comprising largely white, Western

\footnotetext{
4 A significant minority of responses to these two were also ambiguous.
} 
Table 1. Specific artists by name and number of mentions

\begin{tabular}{|c|c|c|c|}
\hline Artist mentioned & Count & Artist mentioned & Count \\
\hline Eminem $^{+}$ & 30 & Bob Dylan ${ }^{+}$ & 7 \\
\hline Kanye West ${ }^{+}$ & 23 & Mastodon $^{+}$ & 7 \\
\hline Megan Trainor ${ }^{-}$ & 17 & Rhianna $^{-}$ & 7 \\
\hline Johnny Cash ${ }^{+}$ & 13 & Guns n Roses $^{+}$ & 7 \\
\hline The Weekend $^{+}$ & 13 & $\mathrm{ACDC}^{+}$ & 6 \\
\hline Led Zeppelin ${ }^{+}$ & 12 & $\mathrm{Bach}^{+}$ & 6 \\
\hline Breaking Benjamin ${ }^{-}$ & 11 & Pink $^{-}$ & 6 \\
\hline Iron Maiden $^{+}$ & 11 & Rammstein $^{+}$ & 6 \\
\hline Tupac Shakur ${ }^{+}$ & 11 & MAGIC! $^{-}$ & 6 \\
\hline Young Guns ${ }^{+}$ & 11 & Sturgill Simpson $^{+}$ & 6 \\
\hline Lana Del Rey ${ }^{+}$ & 11 & Beethoven $^{+}$ & 6 \\
\hline Pantera $^{+}$ & 10 & Bruno Mars $^{+}$ & 5 \\
\hline Five Finger Death Punch ${ }^{+}$ & 11 & Childish Gambino $^{+}$ & 5 \\
\hline Snoop Dogg ${ }^{+}$ & 9 & Sebastian Allen $\mathrm{Coe}^{+}$ & 5 \\
\hline Waylon Jennings $^{+}$ & 9 & Miley Cyrus ${ }^{-}$ & 5 \\
\hline Linkin Park ${ }^{-}$ & 9 & Hatebreed $^{+}$ & 5 \\
\hline Rolling Stones $^{+}$ & 9 & Judas Priest $^{+}$ & 5 \\
\hline Taylor Swift $^{-}$ & 9 & Manowar ${ }^{+}$ & 5 \\
\hline Atmosphere $^{+}$ & 8 & Nicki Minaj- $^{-}$ & 5 \\
\hline Hopsin $^{+}$ & 8 & Modest Mouse $^{+}$ & 5 \\
\hline Seether $^{+}$ & 8 & $\mathrm{Sia}^{-} \mathrm{Cl}$ & 5 \\
\hline The Beatles ${ }^{+}$ & 7 & System of a Down ${ }^{+}$ & 5 \\
\hline Britney Spears ${ }^{-}$ & 7 & Tool $^{+}$ & 5 \\
\hline Drake $^{-}$ & 7 & Volbeat $^{+}$ & 5 \\
\hline Dr. Dre ${ }^{+}$ & 7 & Hank Williams ${ }^{+}$ & 5 \\
\hline
\end{tabular}

${ }^{+}$Indicates majority positive mentions; - indicates majority negative mentions.

men who hold misogynistic and antiegalitarian views, there is indeed indication of a strong preference for rap, metal and hip hop. However, conversely, $68 \%$ of the posts did not include a positive mention of one of these three and $50 \%$ did not positively mention rock, hip-hop, rap, metal or country. This means that, while these genres are disproportionately represented, there is a wider range of music tastes among individuals within this community than might be expected, although only $12 \%$ of posts made a positive evaluation of more than one genre, indicating low degrees of musical omnivoracity.

\section{Artists}

In terms of artists, there were only 50 specifically named artists who had five or more mentions (Table 1). This indicates that there is a good deal of diversity around artist preference even within this community. The highest number of mentions for a specific artist was only 30 (less than 3\% of the total sample); however, Eminem and Kanye West had far more mentions than all other artists. All comments about Eminem were positive, whereas opinions on Kanye West were only slightly more positive than negative. Most of the artists were also fairly well known or 'mainstream' choices and there was a lack of emphasis on niche or 'underground' music. This indicates a desire to both critique and engage with musics with which 
Table 2. Negative evaluations by number of mentions and percent

\begin{tabular}{|c|c|c|c|}
\hline $\begin{array}{l}\text { Reasons for giving a negative } \\
\text { evaluation }\end{array}$ & $\begin{array}{l}\text { Total } \\
\text { count }\end{array}$ & $\begin{array}{l}\text { Percentage of } \\
\text { total sample }\end{array}$ & $\begin{array}{l}\text { Percentage among those who } \\
\text { gave negative evaluation }\end{array}$ \\
\hline Beta/blue pill lyrics or themes & 103 & 8.8 & 25.4 \\
\hline Dislike generally & 101 & 8.6 & 24.9 \\
\hline $\begin{array}{l}\text { Commercial or commercially } \\
\text { duping }\end{array}$ & 38 & 3.2 & 9.4 \\
\hline $\begin{array}{l}\text { Promoting 'oneitis', } \\
\text { 'pedestalling' or love }\end{array}$ & 32 & 2.7 & 7.9 \\
\hline $\begin{array}{l}\text { Decline of civilisation or } \\
\text { society }\end{array}$ & 26 & 2.2 & 6.4 \\
\hline $\begin{array}{l}\text { Negative mention for another } \\
\text { reason (not categorised) }\end{array}$ & 26 & 2.2 & 6.4 \\
\hline Fake or inauthentic & 23 & 2 & 5.7 \\
\hline $\begin{array}{l}\text { Having female or feminine } \\
\text { audience }\end{array}$ & 23 & 2 & 5.7 \\
\hline Music as a drug & 22 & 1.9 & 5.4 \\
\hline $\begin{array}{l}\text { Promotes views of } \\
\text { 'unreasonable women' }\end{array}$ & 22 & 1.9 & 5.4 \\
\hline SJW or feminist lyrics & 20 & 1.7 & 4.9 \\
\hline Lyrics meaningless or trite & 16 & 1.4 & 3.9 \\
\hline No talent or creativity & 11 & 0.9 & 2.7 \\
\hline $\begin{array}{l}\text { Distracting or emotionally } \\
\text { manipulative }\end{array}$ & 9 & 0.8 & 2.2 \\
\hline Misogynistic or homophobic & 8 & 0.7 & 2.0 \\
\hline Victimising men & 6 & 0.5 & 1.5 \\
\hline Pretentious music or fans & 5 & 0.4 & 1.2 \\
\hline Feminine aesthetics in music & 4 & 0.3 & 1.0 \\
\hline Aggressive & 1 & 0.1 & 0.2 \\
\hline
\end{tabular}

a majority of users would be familiar, which may be either a deliberate political strategy to be 'inclusive', or arises from the fact that these are not primarily online music communities.

Megan Trainor was the third most commonly mentioned artist, although all of these posts were negative. Most of the posts about her used overtly misogynistic language (for example 'bitch' or 'slut') and there was hostility to two songs in particular ('All About that Bass' and 'Dear Future Husband'), which were widely played on radios in English-speaking countries in 2014 and 2015 respectively. The number of mentions she received here may therefore be explained by the intersections of increased popularity of MRA sites and discussions of messages in music from 2014-2016, the airplay that the songs received and what were perceived as the 'feminist messages' of the song. Lana Del Rey was the only female-identified artist in the Top 50 most to receive consistently positive mentions (more on this below).

In fact, only eight of the artists mentioned in the Top 50 identify as women and all of these are solo artists. In contrast, the list contained 18 solo male-identified artists and 24 bands. As Figure 6 indicates, in total only 15\% of total posts named either a band with a woman-identified member or artist, while $91 \%$ referred to entirely male-identified bands or artists (queer and non-binary-identified musicians were completely absent). Negative judgments were also significantly more likely to be exercised in discussions about bands with a female-identified members or female-identified 
Table 3. Positive evaluations by number of mentions and percent

\begin{tabular}{|c|c|c|c|}
\hline $\begin{array}{l}\text { Reasons for giving a positive } \\
\text { evaluation }\end{array}$ & $\begin{array}{l}\text { Total } \\
\text { count }\end{array}$ & $\begin{array}{l}\text { Percentage of } \\
\text { total sample }\end{array}$ & $\begin{array}{c}\text { Percentage among those } \\
\text { who gave positive } \\
\text { evaluation }\end{array}$ \\
\hline Like generally & 419 & 35.7 & 52.4 \\
\hline Masculinist lyrics & 120 & 10.2 & 15.0 \\
\hline $\begin{array}{l}\text { Masculine aesthetic or manly } \\
\text { music }\end{array}$ & 56 & 4.8 & 7.0 \\
\hline $\begin{array}{l}\text { Positive mention of music for } \\
\text { another reason (not categorised) }\end{array}$ & 53 & 4.5 & 6.6 \\
\hline Revealing or speaking the truth & 42 & 3.6 & 5.3 \\
\hline Helps to pick up women & 37 & 3.2 & 4.6 \\
\hline $\begin{array}{l}\text { Get pumped up or help with } \\
\text { exercise }\end{array}$ & 34 & 2.9 & 4.3 \\
\hline $\begin{array}{l}\text { Lyrics without further } \\
\text { specification }\end{array}$ & 33 & 2.8 & 4.1 \\
\hline $\begin{array}{l}\text { Genius, visionary, masterful or } \\
\text { talented }\end{array}$ & 27 & 2.3 & 3.4 \\
\hline Authentic, genuine or real & 26 & 2.2 & 3.3 \\
\hline Masculine audience & 24 & 2 & 3.0 \\
\hline Cognitive or thought-provoking & 22 & 1.9 & 2.8 \\
\hline Complex or technical & 20 & 1.7 & 2.5 \\
\hline Anti-SJW or political correctness & 15 & 1.3 & 1.9 \\
\hline Aggressive & 13 & 1.1 & 1.6 \\
\hline No lyrics & 10 & 0.9 & 1.3 \\
\hline Powerful & 9 & 0.8 & 1.1 \\
\hline $\begin{array}{l}\text { Encouraging confidence or } \\
\text { empowering }\end{array}$ & 7 & 0.6 & 0.9 \\
\hline Provides an escape & 4 & 0.3 & 0.5 \\
\hline Good for health & 3 & 0.3 & 0.4 \\
\hline
\end{tabular}

artists. Seventy-eight per cent of posts which mentioned male-identified artists or bands were discussed in a positive way, compared with $37 \%$ of those which named female-identified artists or bands with female members (d.f. $=1, p=0.000$ ). As others have shown, gender bias in musical judgments and the tendency to denigrate work linked to or produced by women (Sergeant and Himonides 2014; Schmutz and Faupel 2010) seem even more pronounced among this community.

\section{Evaluations}

Generally, as Figure 4 indicates, most posts asserted positive judgments and recommendations; only $35 \%$ of all posts included negative evaluations, although there were significant differences in how many positive and negative posts were made by forum (d.f. $=5, p=0.000$ ). As noted above, this varied by genre. However, the overall trend towards affirmative, positive evaluations is interesting in that, unlike many genre-based communities, which often stress a form of masculine competitiveness through denigration of others' tastes (see McLeod 2001), it may reflect politically strategic attempts by forum members to engage rather than alienate other forum users. Posters also clearly often looked to others for support, confirmation and validation about what they should listen to and how they should behave or feel about specific musics. 


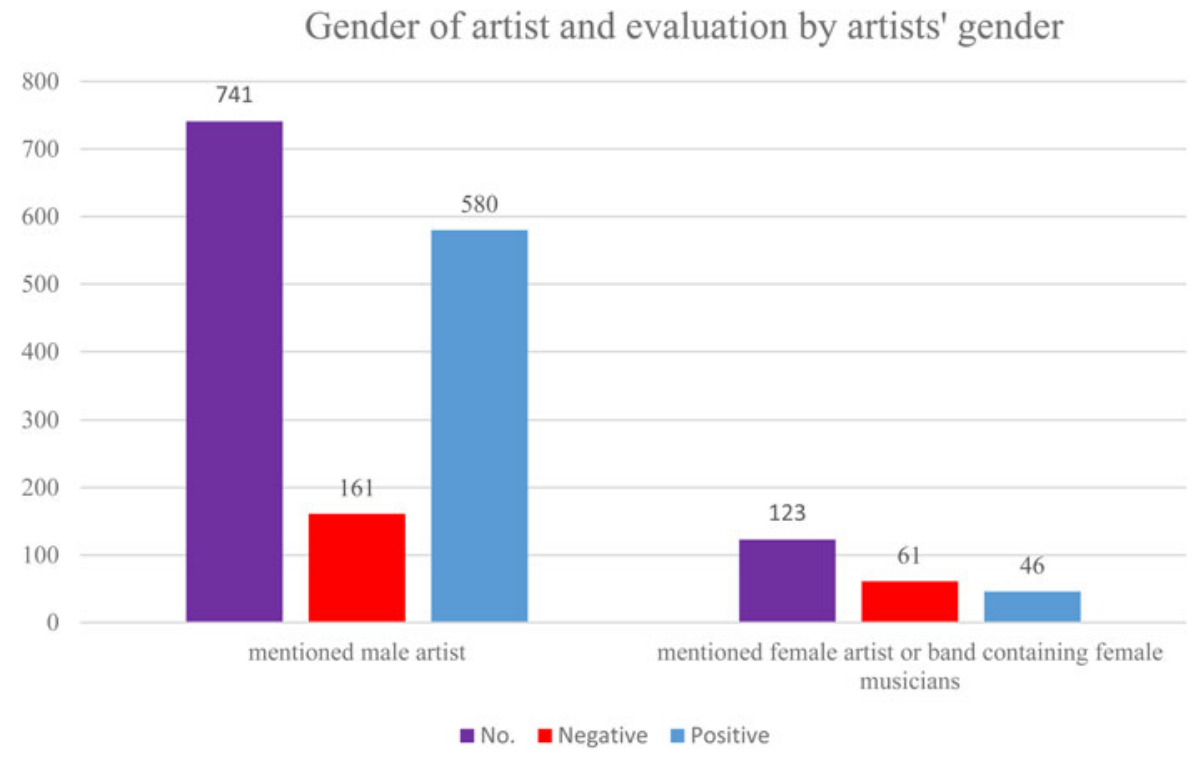

Figure 6. Gender of artist and evaluation by artist's gender.

Some degree of authenticating music taste through peer-confirmation is integral to creating 'taste communities' (McLeod 2001). However, the need for confirmation about music tastes which were appropriate to the forums here perhaps stemmed more from the lack of ontological security offered by genre-based taste communities. Given that there is no (formally) 'misogynistic-musical canon', there was perhaps a greater desire for reassurance in choosing the 'right' kinds of antifeminist, misogynistic music from across genres, than would be expected within genre-based taste communities. Importantly, significantly more negative evaluations were made among those who mentioned 'genres' (48\%) and 'music generally' (54\%) than specific artists (29\% see Figure 3). This is common, however, in that people are more specific about what music they like than what they dislike (see de Boise 2015, pp. 126-34).

\section{Justifications: masculinist aesthetics}

\section{Lyrical masculinism}

The most common reason for positive evaluations of music was that it was 'good' or 'liked generally' (35\%) with no further explanation (see Table 3), which reveals nothing with regards to justification or interpretation. Second to these, however, lyrics emphasising masculinist themes were provided as the main reason that posters gave for liking specific pieces or types of music (10\% of total sample), with $3 \%$ mentioning 'lyrics generally' among the total sample (4\% among those who gave a positive evaluation). In line with the discussion above, 'masculinist themes and lyrics' included any explicit use of evolutionary-inspired terminology (explained further below) as well as more general assessments of how 'masculine' the themes were.

A number of studies have already shown how sexual objectification of women is present to different degrees in rap, rock, Country and Western, hip hop and $R$ ' $n$ ' B 
song lyrics (Flynn et al. 2016). In the data presented here, rap and hip hop genres and artists were linked most commonly in posts to a preference for masculinist lyrical themes (d.f. $=1, p=0.000$ ). However, while sexual objectification clearly accounts for some of the appeal, the emphasis on valorising music which embodies masculinist themes often, in fact, frames women as repulsive rather than objects of desire. As such, there was a greater tendency towards lyrics which emphasise an essentialist belief in men's dominance over women.

For instance, in addition to being the most commonly mentioned artist, Eminem's 'Superman' was mentioned in the majority of positive evaluations of his music, with a strong focus on his lyrics. The song itself contains lines such as:

bitch you make me sick, bitch you make me hurl ... not a jealous man but females lie ... I'll slap you off that bar stool. There goes another lawsuit. Leave handprints all across you.

In addition to explicitly misogynistic language and references to violence against women, the lyrics also invoke essentialist discourses around sexually dimorphic, hardwired differences ('females lie') often found in 'gangsta rap' specifically (Weitzer and Kubrin 2009, p. 10). In this way, both the explicitly misogynistic lyrics and the implicitly masculinist undertones clearly resonate with this community.

Eminem's prominence is also important here given that MAMs tend to skew towards white men. As Kajikawa (2009) notes, Eminem has portrayed himself as an 'underdog' and embracing his own whiteness is one of the means by which he was able to achieve fame and notoriety. He has thus also been embraced by nationalist and right-wing extremist imaginaries, where identification with his 'underdog' status is a means to confirm notions of economic oppression faced by white men in contemporary society, while simultaneously asserting the inherent superiority of white men to overcome these obstacles and excel in a musical form emerging from African diasporas (Teitelbaum 2017, pp. 66-7). Both his persona and masculinist lyrics therefore play into MAM fantasies of 'white male victimhood'.

The concept of 'alpha' attitudes or lyrics was one of the most common words associated with positive judgments around lyrics $(4.5 \%$ of total cases and $10 \%$ among those who gave a positive reason, d.f. $=1, p=0.000$ ). As Ging (2017) notes, the concept of 'being alpha' itself is prominent on MAM forums because it suggests recourse to a biologically essentialist understanding of gender; namely that there are 'naturally hardwired' behavioural differences based on sexual dimorphism that are distinct from, and uninfluenced by, culture. The figure of the 'alpha male' is of paramount importance to MAMs and the 'manosphere' more generally, insofar as it promotes and sustains a masculinist fantasy that there really is a naturally existing gender hierarchy in which men are naturally superior to women.

To this end, an emphasis on themes which imply 'alpha' dominance were also invoked in positive evaluations of Lana Del Rey's lyrics who, as noted, was the only female-identified artist to receive consistently positive mentions. These were directly linked to her 'red pill' 5 and 'alpha-widow' lyrics with song titles such as 'Fucked my Way to the Top' and 'You can be the Boss', receiving special praise for emphasising

\footnotetext{
5 'Red pill' and 'blue pill' are references to the film The Matrix (1999), extremely popular with young men at the time. This recalls a scene in which the main character is asked to choose between a red pill, allowing him to see reality as it is, a miserable dystopian future where humans are harvested for fuel by robots, and a blue pill, allowing him to keep living in an illusory state.
} 
what was perceived to be a 'woman's perspective' on masculinist dominance. 'You can be the Boss', for example, contains the lyrics:

The liquor on your lips makes you dangerous ... I tried to be strong but I lost it ... You can be the boss, daddy ... You can be the boss.

Here, the invocation of a patriarchal euphemism ('daddy') combined with the implication of sexual submissiveness ('I tried to be strong but I lost it') plays into particular masculinist fantasies of natural gender roles and essentialist hierarchies in which women subconsciously desire domination by 'real' (i.e. alpha) men.

As also noted above, analysing music distaste reveals how men's identities are constructed in opposition to generalised others. As such, while the notion of 'alpha male' suggests a discursive superiority of men over women, it also implies a natural hierarchy between men. Indeed, as masculinities scholars have shown, men's own gender expressions and identities are often confirmed in relation to and distinction from 'other' men, as well as people of other genders (Aboim 2010; Connell 1995). To this end, lyrics, and specifically 'beta' and 'blue pill' lyrics, were the main reason provided for disliking music.

The genres demonstrating the strongest relationship with 'beta/blue pill lyrics' were pop ( $26 \%$ d.f. $=1, p=0.001)$, rock $(17 \%$ d.f. $=1, p=0.000)$ and music described as 'mainstream/commercial' (11\% d.f. $=1, p=0.000)$. Indie rock and emo subgenres, also featured prominently $(10 \%$ d.f. $=1, p=0.000)$. Looking at the specific lyrics mentioned in judgments of 'blue pill/beta lyrics', many included themes of unrequited love as well as expressing what was considered self-pity and/or adoration of women. A hostility to these themes was also evidenced in negative mentions of lyrics which emphasised 'oneitis' or 'pedastalling' $(2.7 \%$ among the total, $7.9 \%$ among those who gave a negative evaluation). These terms, used commonly in these communities, treat pejoratively the idea that there is one 'perfect woman' for every man - which was seen to go against a particular sociobiological view on men's nature as sexually promiscuous (see Connell 1995) - or the idea that women should be put on a pedestal - which was seen as an outcome of feminism's 'cultural domination' and oppression of men (García-Favaro and Gill 2016).

Judgments of lyrical themes surrounding love and romance as 'unmasculine', by contrast, have a long history of condemnation in 'melancholic' music, especially, due to the belief that it compromises notions of rational, masculine individualism through dependence and the loss of autonomy (de Boise 2014). Again, this is seen as both a perversion of the 'natural' gender order, in the essentialist notion that men are biologically predisposed towards non-monogamy, combined with a more general disdain for qualities discursively associated with femininity, such as emotional expression, love and romance.

\section{Musical masculinism}

As Table 3 also shows, in addition to lyrics, the next most common reason for positive evaluations of music was linked to a belief that the music itself could be considered 'masculine' or 'manly'. Metal was undeniably the genre category with the strongest relationship with this variable (d.f.=1, $p=0.000)$. Nonetheless, while a significant number of those who mentioned 'masculine or manly music' also mentioned hip hop or rap, there were no statistically significant 
relationships between these variables. This suggests that this community primarily engages with rap and hip hop based on lyrics and racialised stereotypes, rather than sound (for discussions on 'hypermasculinity' as racialised, see Segal 1990; Fried 1996).

As noted above, metal has been linked explicitly in previous research to promoting misogyny. Yet there were no significant relationships between positive attitudes to metal and mentioning masculinist lyrics. Instead metal was more likely to be linked to encouraging more general feelings of 'aggression', 'power' or 'getting pumped' (d.f. $=1, p=0.000$ ) or for embodying a 'manly/masculine' aesthetic. The relationship of metal to judgments around 'masculine/manly music', especially, thus suggests an identification with specific sonic properties which are judged to correspond to masculinism espoused among MAM communities.

From a sociological perspective, metal has long been considered a space that encourages a highly homosocial (Hill 2016), even homoerotic, corroboration of masculine performance, as well as expressions of 'masculine individualism' (Rafalovich 2006). Yet, musically, its focus on distortion, high volumes and fast tempos appears to be important for this community, signifying musical masculinism through:

impressive technical and rhetorical feats on the electric guitar, counterposed with an experience of control and power that is built up through vocal extremes, guitar power chords, distortion, and sheer volume of bass and drums. (Walser 1993, p. 103)

The idea that distortion, fast tempos and high volumes are read as a form of aesthetic masculinism among this group is further supported by comments about punk/hardcore. While punk and hardcore punk were much less frequently mentioned overall, occasionally receiving criticism for links to their promotion of 'social justice warrior' narratives (d.f. $=1, p=0.000$ ), there were also statistically significant relationships between liking punk/hardcore and positive evaluations around 'manly/masculine music' (d.f. $=1, p=0.017$ ).

As Williams (2007, p. 152) observes, punk and hardcore variants sonically communicate 'aggression, anguish, frustration and even emotional vulnerability ... through breakneck tempos, harsh, gritty vocal timbres, and very little deviation from simple, formal structures'. Thus, here again, sonic markers judged to communicate aggression, power and control undoubtedly go some way to explaining the musical appeal of these genres for this community in that they correspond to an aesthetic masculinism based on essentialist beliefs of men's inherent superiority, dominance, control and aggression. Yet it also suggests a frustration and insecurity about their identities which is linked to the broader politics of MAMs around 'men as victims'. Thus, I would suggest that both the sonic and the extra-musical/social dimensions of metal, in tandem with the group's politics, explain its aesthetic appeal among this group.

In addition to these more audibly 'masculine' sounds, Western classical and orchestral music also had a strong relationship to positive evaluations as 'manly' or 'masculine' music (d.f. $=1, p=0.003$ ). Feminist musicologists have long observed that the structural foundations of non-lyrical music are influenced by gendered discourse and that it is possible to read masculine themes in classical music (McClary 1991). Furthermore, not only has the Western musical cannon tended to exclude women, but the treatment of composers within the canon as 'geniuses' draws on a long tradition of 'absolute music' which has tended to discursively disavow the 
embodied, and to emphasise the rational or cognitive dimensions of composition in gendered and racialised ways (Citron 1993).

In fact, belief in Western classical music as 'masculine' here intertwines subtly with the racial geopolitics of MAMs. For instance, in the international bestseller 12 Rules for Life (2018), Jordan Peterson, an 'intellectual figurehead' within the community, claims that:

When a lobster that has just lost a battle is exposed to serotonin, it will stretch itself out, advance even on former victors, and fight longer and harder ... That same brutal principle of unequal distribution applies outside the financial domain - indeed, anywhere that creative production is required ... Similarly, just four classical composers (Bach, Beethoven, Mozart, and Tchaikovsky) wrote almost all the music played by modern orchestras. (Peterson 2018, pp. 27-8)

In the space of a page, Peterson's reasoning moves from linking lobster serotonin to natural male aggression (a biologically suspect argument) to implying men's supposedly naturally competitive behaviour as the reason for Beethoven, Mozart and Bach's collective canonisation. This quote crystallises the discursive relationship between masculinism as an ideology and positive aesthetic evaluations relating to well-known classical composers among MAM communities. Firstly, as with heavy metal which 'often stages fantasies of masculine virtuosity and control' (Walser 1993, p. 103), virtuosity is regarded as a form of 'masculine individualism' historically associated with 'natural genius' (see Battersby 1989). This is both a simultaneously 'gender-blind' and a gendered discourse in that it treats musical value as objective, while failing to recognise the political and economic forces behind canonisation. In addition, however, the 'great man of history' narrative invokes a gendered and racialised politics equating the cultural superiority of Western classical music to that of 'Western civilisation' (DeNora 1997; Forth 2008). This reasoning is used tautologically to explain the music's inherently greater aesthetic value, because it has been composed by white men during periods of intense social exclusion. Thus, both history and tradition are inseparable from masculinist aesthetics.

Instead of referencing specific sonic components, negative reactions with respect to (non-lyrical) musical features centred on accusations of inauthenticity and commercial duplicity (see Table 2). Again, 'pop' displayed the strongest link to accusations of either commercially duping people or displaying a lack of authenticity ( $9 \%$ among those who negatively evaluated pop, d.f. $=1, p=0.000$ ). There were also significant relationships between negative evaluations of pop $(p=0.000)$ and 'mainstream/commercial' music $(p=0.005)$ based on the presumption of a feminine audience, with arguments around the 'feminisation of pop music' offered in comments often as a tautological reason for pop's perceived lesser value. Thus accusations of inauthenticity rest on pop's perceived links to younger female audiences, its foregrounding of vocally trained (largely female-identified and/or 'femme') singers and a relegation of guitar, bass and drums to the background as 'unmasculine' (Railton 2001; Kruse 2002).

This suggests that a belief in an aesthetic masculinism (the idea of 'the masculine' as inherently superior to 'the feminine'), based on intra- and extra-musical judgments, is used as an a priori justification for pop music's poor quality. Indeed, the idea of commercially produced pop music as inauthentic echoes well-established critiques from cultural theorists which have denigrated music associated with embodied pleasure and enjoyment (McClary 1991, p. 28). Thus there is an equation, 
again, of 'the masculine' and masculinist aesthetics with authenticity, and a naturally ordered social hierarchy and pop music with manipulation, inauthenticity, artifice and thus alienation from the natural state. This rests more generally on the politics of emotional authenticity in music as fundamentally gendered (de Boise 2015).

\section{Nostalgia, crisis and decline}

As noted above, discussions of 'music generally' included far more negative than positive evaluations (see Figure 5). Some $11 \%$ of those who mentioned 'music generally' expressed notions of a decline in musical quality $(p=0.002)$, with notions of 'civilisational or societal decline' making up $6 \%$ of posts among those which gave a negative evaluation. Notions of 'decline' correspond more generally to MAMs' worldview of societies in which cultural products have been 'tainted' by the influence of feminism and/or equality legislation (Ging 2017; Chowdhury 2014; Blais and Dupuis-Déri 2012). To this end, there were noticeably persistent references to 'how things used to be', and an affective nostalgia for a 'lost' form of masculinity.

Music which in some way was perceived as 'revealing the truth' about this decline was also rated as one of the specific positive reasons for liking music. Rap $(p=0.002)$, hip hop $(p=0.000)$ and rock $(p=0.026)$ demonstrated statistically significant relationships with positive evaluations of music which 'revealed the truth'. Again, much of this relates to ideas around natural hierarchies between men and women, and the perceived subversion of these as a result of feminism. This also explains particularly strong reactions against songs deemed to be feminist. For example, Megan Trainor came under fire for her lyrics in 'Dear Future Husband', in which the female narrator asks her (presumably male) partner to do minor domestic chores and be attentive. This was repeatedly interpreted as evidence of societal decline linked to women's right to choose at the expense of men. As such, music which either attracted a 'feminine audience' or emphasised social critique from the 'point of view of women' was typically disliked (see Table 2).

However notions of decline and crisis were perhaps best illuminated by recurrent positive references to 'classic rock' from the 1960s and 1970s - the Rolling Stones, Led Zeppelin and AC/DC especially - as representing the pinnacle of musical masculinism ('when men where men'). The canonical function of male rockstars in established histories of Western popular music has been built by what McLeod (2001, p. 56) argues is the 'cumulative effect' of writing about-men-by-men in rock criticism. As noted above, a number of authors have also pointed to the particular gendered dimensions of this division between pop as inauthentic and rock as authentic (Kruse 2002; Frith and McRobbie 1978). Classic rock's status as masculine was further justified here by references to songs which deal directly with heterosexual promiscuity ('Whole Lotta Rosie'; 'Whole Lotta Love') and control over women ('Under my Thumb') underscored by performances of 'hypermasculine' sexuality (Frith and McRobbie 1978) and public personae crafted around sexual mastery and autonomy.

All this builds on narratives around rock as sustained through discourses of masculine freedom, independence and individualism (Leonard 2007). However I would suggest that nostalgic emphasis on 'classic rock' here also reflects broader political discourse of a 'traditional masculinity' in 'crisis' or 'decline', within masculinist movements (Brittan 2001). The notion that the 1960s and 1970s represented a lost golden age for 'masculine music', dovetails neatly with a linear chronology of 
women's and civil rights as well as progressive social movements since the 1960s. However, discourses around 'crisis' have been invoked (effectively) with regards to masculinity since the 1700 s in periods of social and economic change (Forth 2008, pp. 37-40). Thus, the idea that the fortunes of a specific notion of white masculinity are bound up with the ageing of 'classic rock stars' since the 1970s relies both on the affective function of discourses around 'classic rock's' gendered canonisation (see Leonard 2007) and on the latest incarnation of masculinity in crisis, rather than any real decline in men's economic or social power.

\section{Conclusions}

This article has shown that those associated with MAMs, movements defined by members with openly misogynistic views, are more likely to express preference for rap, metal and hip hop. This supports a good deal or research, specifically around these genres' links to misogynistic attitudes and beliefs. However, as observed, musical interpretations linked to misogyny across a range of musics are filtered, confirmed and amplified through and by the virtual and physical communities that these individuals immerse themselves in. In contrast to previous research, this study indicates that those who espouse openly misogynistic views are drawn to a wider spectrum of music genres - particularly Country and Western, rock, electronic dance music and Western classical - than the oft-invoked trinity of rap, hip hop or metal. The most commonly named artists were also fairly well-known, 'mainstream' figures, suggesting that this community is not particularly niche or discerning musically. It could be speculated, however, that owing to the desire to 'recruit' participants, this may also be a strategy for inclusivity.

Song lyrics were the main reason behind both liking and disliking music, with lyrics which emphasise masculinist worldviews a driving force in explaining music tastes among this group. Forum users were more likely to fixate on lyrics emphasising masculinist themes in rap, country, rock and hip hop than other genres. Songs about love and romance, particularly in pop, emo and indie genres were much more likely to attract negative condemnation owing to their links to 'beta male' identities and ultimately a perceived femininity.

Amongst the non-lyrical reasons for liking music, sonic qualities such as distortion, fast tempos and high volumes, frequently taken to signify aggression, power or strength, were seen as sonically embodying aesthetic masculinism. Metal was often linked to this, but punk/hardcore also demonstrated statistically significant relationships. However, there were also statistically significant relationships between Western classical and expressing positive evaluations around 'masculine or manly' aesthetics. This is probably influenced by the high status that classical music still holds, and a belief in the inherent superiority of music linked to Western European art traditions which have been endemically white and patriarchal. Gendered assumptions of inauthenticity and commercialism in 'pop' music were a key reason for disliking the genre, its supposed inauthenticity linked to judgments around sonic or cultural 'feminisation'.

Finally, more general notions of 'societal or civilisational decline', linked to a belief in the decline of the cultural value of 'traditional masculinity', were provided as primary reasons for disliking music more generally. Thus among this group, an identification with certain masculinist aesthetics and distancing from music which was taken to represent 'unnatural' or 'aberrant' gendered expressions, was coupled 
to an emphasis on the apex of 'traditional masculinity' as intertwined with the canonisation of classic rock. This indicates that extra-musical, discursive factors play as much a role in interpreting and judging the specific musical qualities, as the lyrics or the sounds of music.

\section{References}

Aboim, S. 2010. Plural Masculinities: the Remaking of Self in Private Life (Farnham, Ashgate)

Aubrey, J.S., Hopper, K.M., and Mbure, W.G. 2011. 'Check that body! The effects of sexually objectifying music videos on college men's sexual beliefs', Journal of Broadcasting $\mathcal{E}$ Electronic Media, 55/3, pp. 360-79

Barongan, C., and Nagayama, G.C. 1995. 'The influence of misogynous rap music on sexual aggression against women', Psychology of Women Quarterly, 19/2, pp. 195-207

Battersby, C. 1989. Gender and Genius: Towards a Feminist Aesthetics (London, The Women's Press)

Blais, M., and Dupuis-Déri, F. 2012. 'Masculinism and the antifeminist countermovement', Social Movement Studies, 11/1, pp. 21-39

Brittan, A. 2001. 'Masculinities and masculinism', In The Masculinities Reader, ed. S. Whitehead and F.J. Barrett (Cambridge, Polity Press), pp. 51-5

Chowdhury, R. 2014. 'Conditions of emergence: the formation of men's rights groups in contemporary India', Indian Journal of Gender Studies, 21/1, pp. 27-53

Citron, M. 1993. Gender and the Musical Canon (Champaign, IL, University of Illinois Press)

Connell, R. 1995. Masculinities (Cambridge, Polity Press)

Cook, S., and Tsou, J. 1994. Cecilia Reclaimed: Feminist Perspectives on Gender and Music. (Champaign, IL, University of Illinois Press)

de Boise, S. 2014. 'Cheer up emo kid: rethinking the "crisis of masculinity" in emo', Popular Music, 33/2, pp. 225-42

de Boise, S. 2015. Men, Masculinity, Music and Emotion (London, Palgrave Macmillan)

DeNora, T. 1997. Beethoven and the Construction of Genius: Musical Politics in Vienna, 1792-1803 (Oakland, CA, University of Calinfornia Press)

DiNitto, D., Busch-Armendariz, N, Bender, K, Woo, H, Tackett-Gibson, M., and Dyer, J. 2008. 'Testing telephone and web surveys for studying men's sexual assault perpetration behaviors', Journal of Interpersonal Violence, 23/10, pp. 1483-93

Dragiewicz, M. 2011. Equality with a Vengeance: Men's Rights Groups, Battered Women, and Antifeminist Backlash (Boston, MA, Northeastern University Press)

Dyck, K. 2017. Reichsrock: The International Web of White-Power and Neo-Nazi Hate Music (Brunswick NJ, Rutgers University Press)

Eynon, R., Schroeder, R., and Fry, J. 2009. 'New techniques in online research: challenges for research ethics', Twenty-First Century Society, 4/2, pp. 187-99

Faludi, S. 1992. Backlash: The Undeclared War Against American Women (London, Chatto \& Windus)

Ferber, A.L. 2000. 'Racial warriors and weekend warriors: the construction of masculinity in mythopoetic and white supremacist discourse', Men and Masculinities, 3/1, pp. 30-56

Fischer, P., and Greitemeyer, T. 2006. 'Music and aggression: the impact of sexual-aggressive song lyrics on aggression-related thoughts, emotions, and behavior toward the same and the opposite sex', Personality and Social Psychology Bulletin, 32/9, pp. 1165-76

Flynn, M.A., Craig, C.M., Anderson, C.N., and Holody, K.J. 2016. 'Objectification in popular music lyrics: an examination of gender and genre differences', Sex Roles, 75/3, pp. 164-76

Forth, C.E. 2008. Masculinity in the Modern West: Gender, Civilization and the Body (Basingstoke, Palgrave Macmillan)

Fried, C.B. 1996. 'Bad rap for rap: bias in reactions to music lyrics', Journal of Applied Social Psychology, 26/23, pp. 2135-46

Frith, S., and McRobbie, A. 1978. 'Rock and sexuality', Screen Education, 29, pp. 3-19

García-Favaro, L., and Gill, R. 2016. "Emasculation nation has arrived": sexism rearticulated in online responses to Lose the Lads' Mags campaign', Feminist Media Studies, 16/3, pp. 379-97

Garrido, S., and Schubert, E. 2013. 'Adaptive and maladaptive attraction to negative emotions in music', Musicae Scientiae, 17/2, pp. 147-66

Ging, D. 2017. 'Alphas, betas, and incels: theorizing the masculinities of the Manosphere', Men and Masculinities [Online First]. doi:10.1177/1097184×17706401.

Gotell, L., and Dutton, E. 2016. 'Sexual violence in the "Manosphere": antifeminist men's rights discourses on rape', International Journal for Crime, Justice and Social Democracy, 5/2, pp. 65-80

Henry, P.J. 2008. 'College sophomores in the laboratory redux: influences of a narrow data base on social psychology's view of the nature of prejudice', Psychological Inquiry, 19, pp. 49-71

Hill, R.L. 2016. Gender, Metal and the Media (London, Palgrave Macmillan) 
Iwamoto, D. 2003. 'Tupac Shakur: understanding the identity formation of hyper-masculinity of a popular hip-hop artist', The Black Scholar, 33/2, pp. 44-9

Jane, E.A. 2016. Misogyny Online: A Short (and Brutish) History (London, Sage)

Jarman-Ivens, F. 2006. 'Queering masculinities in heterosexist rap music', in Queering the Popular Pitch, ed. S. Whitely and J. Rycenga (London: Routledge), pp. 199-220

Järviluoma, H., Moisala, P., and Vilkko, A. 2003. 'Not only vision - analysing sound and music from the perspective of gender', in Gender and Qualitative Methods (London, SAGE), pp. 84-107

Kajikawa, L. 2009. 'Eminem's "my name is": signifying whiteness, rearticulating race', Journal of the Society for American Music, 3/3, pp. 341-63

Kimmel, M. (ed.) 1995. The Politics of Manhood: Profeminist Men Respond to the Mythopoetic Men's Movement (and the Mythopoetic Leader's Answer) (Philadelphia, Temple University Press)

Kistler, M.E., and Lee, M.J. 2009. 'Does exposure to sexual hip-hop music videos influence the sexual attitudes of college students?' Mass Communication and Society, 13/1, pp. 67-86

Kruse, H. 2002. 'Abandoning the absolute: transcendence and gender in popular music discourse', in Pop Music and the Press, ed. S. Jones (Philadelphia, PA, Temple University Press), pp. 134-55

Lawrence, J., and Joyner, D. 1991. 'The effect of sexually violent rock music on males' acceptance of violence against women', Psychology of Women Quarterly, 15, pp. 49-63

Leonard, M. 2007. Gender in the Music Industry: Rock Discourse and Girl Power. (Aldershot, Ashgate)

Lozon, J., and Bensimon, M. 2014. 'Music misuse: a review of the personal and collective roles of "problem music"', Aggression and Violent Behavior, 19/3, pp. 207-18

Lynn, A.B. 2014. 'The women of the men's rights movement: inside the online world of honey badgers, trolls, and feminist threats'. https://www.vice.com/sv/article/znwwva/the-women-of-the-mens-rights-movement751 (accessed 28 September 2018)

McClary, S. 1991. Feminine Endings: Music, Gender and Sexuality (Minneapolis, MN: University of Minnesota Press)

McLeod, K. 2001. 'One and a half stars: a critique of rock criticism in North America', Popular Music, 20/1, pp. $47-60$

McLeod, K. 2009. 'The construction of masculinity in african american music and sports', American Music, 27/2, pp.

Mellström, U. 2016. 'In the time of masculinist political revival', NORMA, 11/3, pp. 135-8

Messner, M. 1998. 'The limits of "the male sex role": an analysis of the men's liberation and men's rights movements' discourse', Gender \& Society, 12/3, pp. 255-76

Moi, T. 2006. "II am not a feminist, but. . .": how feminism became the F-word', PMLA, 121/5, pp. 1735-1741

Moisala, P., and Diamond, B. 2000. Music and Gender (Champaign, IL, University of illinois Press)

Nagle, A. 2017. Kill All Normies: Online Culture Wars from 4Chan and Tumblr to Trump and the Alt-Right (Alresford, Zero Books)

Neuendorf, K. 2017. The Content Analysis Guidebook (London, Sage)

O’Neill, R. 2018. Seduction: Men, Masculinity and Mediated Intimacy (London, Polity Press)

Peterson, J. 2018. 12 Rules for Life: An Antidote to Chaos (Toronto, Random House Canada)

Rafalovich, A. 2006. 'Broken and becoming god-sized: contemporary metal music and masculine individualism', Symbolic Interaction, 29/1, pp. 19-32

Railton, D. 2001. 'The gendered carnival of pop', Popular Music, 20/3, pp. 321-31

Schmutz, V., and Faupel, A. 2010. 'Gender and cultural consecration in popular music', Social Forces, 89/2, pp. 685-97

Segal, L. 1990. Slow Motion: Changing Masculinities, Changing Men (London, Virago)

Sergeant, D., and Himonides, E. 2014. Gender and the performance of music. Frontiers in Psychology, 5. doi:10.3389/fpsyg.2014.00276.

Shekhovtsov, A. 2012. 'European far-right music and its enemies', in Analyzing Fascist Discourse: European Fascism in Talk and Text, ed. R. Wodak and J.E. Richardson (London, Routledge, pp. 277-96

Sugiura, L., Wiles, R., and Pope, C. 2017. 'Ethical challenges in online research: public/private perceptions', Research Ethics, 13/3-4, pp. 184-99

Teitelbaum, B. 2017. Lions of the North: Sounds of the New Nordic Radical Nationalism. (New York, Oxford University Press)

Volgsten, U. 2006. 'Between ideology and identity', in Music and Manipulation: On the Social Uses and Social Control of Music, ed. S. Brown and U. Volgsten (Oxford, Berghan Books), pp. 74-102

Walser, R. 1993. Running with the Devil: Power, Gender and Madness in Heavy Metal Music (Hanover, NH, Weslyan University Press)

Weitzer, R., and Kubrin, C. 2009. 'Misogyny in rap music: a content analysis of prevalence and meanings', Men and Masculinities, 12/1, pp. 1-27

Wester, S.R., Crown, C.L., Quatman, G.L., and Heesacker, M. 1997. 'The influence of sexually violent rap music on attitudes of men with little prior exposure', Psychology of Women Quarterly, 21/4, pp. 497-508

Williams, S. 2007. '“A walking open wound': emo rock and the crisis of masculinity in America', in Oh Boy!: Masculinities and Popular Music, ed. F. Jarman-Ivens, pp. 145-60 (London, Routledge)

Wilson, K. 2018. 'Red pillers, sad puppies and gamergaters: the state of male privilege in internet fan communities', in A Companion to Media Fandom and Fan Studies, ed. P. Booth, pp. 415-30. (London, Wiley Blackwell) 